\title{
Application and Analysis of Modularity in Assembly Unit of Drying and Distribution Unit of Braking System of an Automobile
}

\author{
Abdul Munaf Shaik ${ }^{1, *}$, V V S. Kesava $\operatorname{Rao}^{2}$, Ch. Srinivasa Rao ${ }^{2}$ \\ ${ }^{1}$ Vasireddy Venkatadri Institute of Technology, India \\ ${ }^{2}$ Andhra University College of Engineering, India
}

Copyright (C) 2015 Horizon Research Publishing All rights reserved.

\begin{abstract}
Modularity is a general concept, and many engineering problems can be generalized under the umbrella of modularity. Special structure of products poses challenges in the design of assembly systems which involves layout design, buffer design, line balancing, and transportation design and resource selection. An assembly line of Drying and Distribution Unit of an automobile has been selected for analysis and application of modularity. Assembly times at individual stations during different times of a day have been observed and analyzed. Modularity has been applied on the assembly line to minimize the total assembling time and idle time. It was found that the total number of components assembled has been increased by $7 \%$ after applying modularity. Flexsim simulation software has been used to simulate the assembly line, before and after applying the modularity and the results have been compared.
\end{abstract}

Keywords Modular Manufacturing, Assembly Line, Modularization, Product Modualrity, Assembling Time, Modular Design

\section{Introduction}

Modularity has attracted the attention of many researchers in the field of manufacturing, architecture, design and assembly. The modularization in the industry has involved architectural changes in product, production and assembly operations emphasizing different purposes and aspects. Assembly lines are special flow-line production systems which are of great importance in the industrial production of high quantity standardized components. Recently, assembly lines even gained importance in low volume production of customized products (mass-customization). The modularity design and modularity manufacture of product had been used widely in aircraft, automobiles, consumer electronics, household appliances computers, software, measuring instruments and power tools. Modularization in Auto Industry varies between regions and companies; even then there exists large number of units with relatively common features in the industry. As a result of these different practices, modularization in Auto industry can be viewed in three facets, i) Modularization in product architecture, ii)Modularization in production and iii) Modularization in inter-firm system. Product modularization has the potential to give a number of benefits for a manufacturing firm. However, the modularization process and the division of a product into a number of modules is not a simple task. Six different modularization methods viz., Fractal product Design, Modular Product Development, Modeling the Product Modularity, Modular Function Deployment, Design Structure Matrix and Axiomatic Design, for dividing a product into suitable modules, analyzed to know their ability to deal with the different degrees of product complexity. The present paper deals with the application of modularity in an assembly line of Drying and Distribution Unit of an automobile plant and analysis.

\section{Experimentation}

An assembly line of Drying and Distribution Unit of an automobile plant has been selected in order to collect sample data. The considered component is used in the braking system of Automobiles (Fig: 1).The assembly line of the component has nine stations and in each station, some of the parts are attached to the main body. The time consumed for adding parts to the assembly at each station has been measured and tabulated. This data has been collected at different times of the day like at the start of the shift, just before lunch, after lunch, before tea time and just before end of the shift. The same has been repeated for a five days. The average time taken at each station for assembling and the standard deviation values are shown in the Table: 1 . 
Table 1. The average assembling time taken at each station and the list of components assembled

\begin{tabular}{|c|c|c|c|}
\hline $\begin{array}{c}\text { S1. } \\
\text { No. }\end{array}$ & $\begin{array}{c}\text { Station } \\
\text { No. }\end{array}$ & Parts & $\begin{array}{c}\text { Time } \\
\text { in sec. }\end{array}$ \\
\hline 1 & S1 & Plastic valve, silencer & 258 \\
\hline 2 & S2 & Tyre inflator, screws and washers & 194 \\
\hline 3 & S3 & Plunger, unloaded valve etc. & 242 \\
\hline 4 & S4 & $\begin{array}{c}\text { Non return valve, sealing ring, filter and } \\
\text { valve seat etc. }\end{array}$ & 316 \\
\hline 5 & S5 & $\begin{array}{c}\text { Purge tank, lock nut, cartridge retainer } \\
\text { and sealing ring etc. }\end{array}$ & 291 \\
\hline 6 & S6 & Governor valve & 426 \\
\hline 7 & S7 & $\begin{array}{c}\text { Quadruple system protection valve, ring } \\
\text { guide, top cover etc. }\end{array}$ & 452 \\
\hline 8 & S8 & Pressure setting valve, screws spring etc. & 420 \\
\hline 9 & S9 & Lip seal, stiffener cover etc. & 322 \\
\hline
\end{tabular}

After analyzing the obtained data from conventional assembly line it has been observed that the bottle neck is at station 7 where the Quadruple System Protection Valve
(QSPV) with all individual parts is being added to the assembly. Because of this bottleneck, a slack of few seconds is observed in the consecutive stations. The same has been simulated by using well accepted simulation software Flexsim. The parameters are set as per the actual measurements taken.

To avoid the above mentioned problem and to minimize the slack times of wasting it has been proposed to apply modularity at station 7 . Since there are several small parts in QSPV which is to be assembled in station 7 along with other parts, it has been proposed to assemble the QSPV separately and keep ready stock at station 7 , so that the total number of parts $\mathrm{s}$ assembled in station 7 is minimized. With the proposed modifications, the system has been simulated using Flexsim. The assembling time in station 7 has come down from 452 seconds to 360 seconds. Proposals are submitted with minute modifications in the design and are accepted for implementation at the shop floor level. After applying modularity, the data has been collected and analyzed.

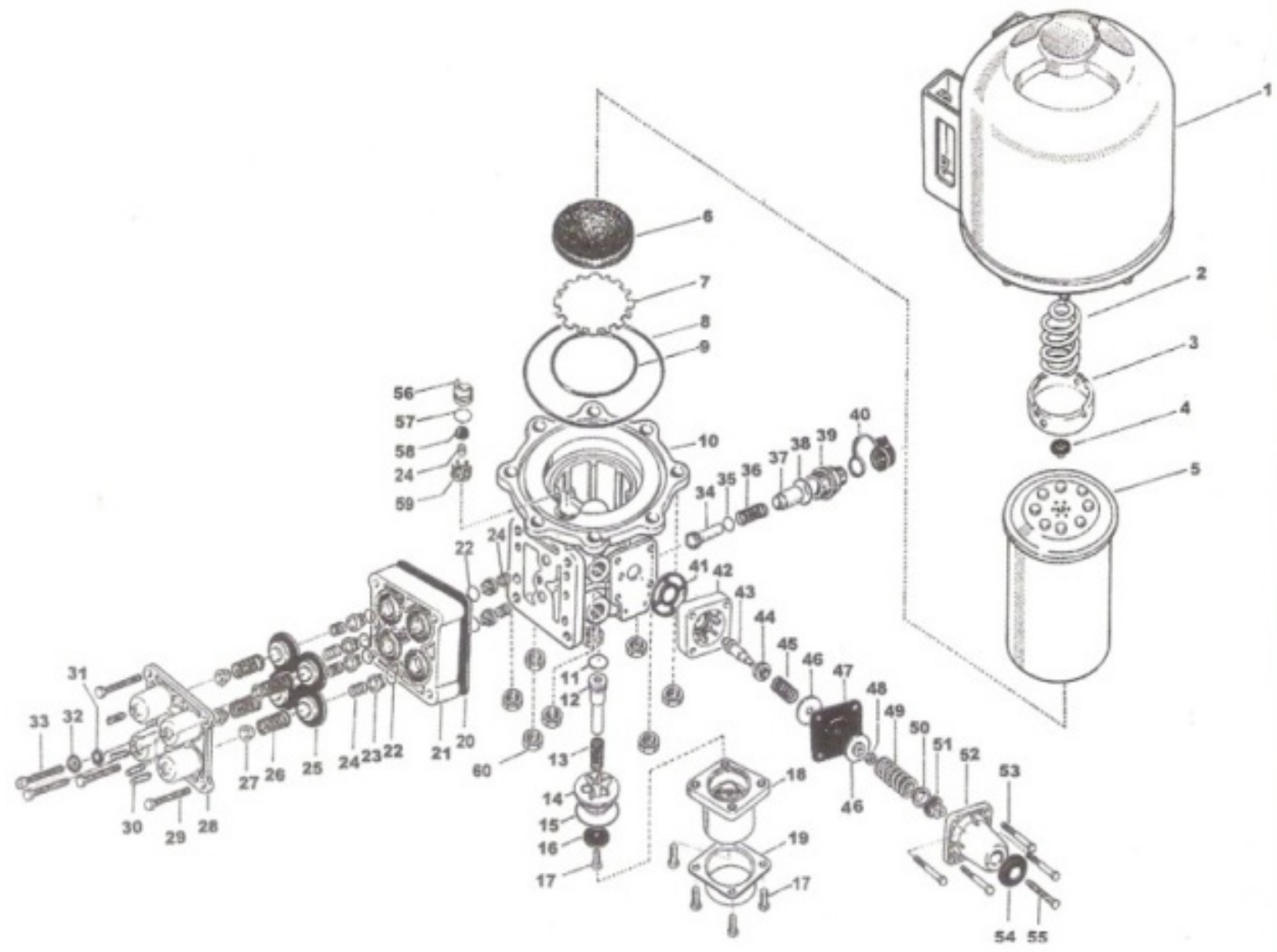

Figure 1. Exploded view of a Drying and Distribution Unit of a braking system. 


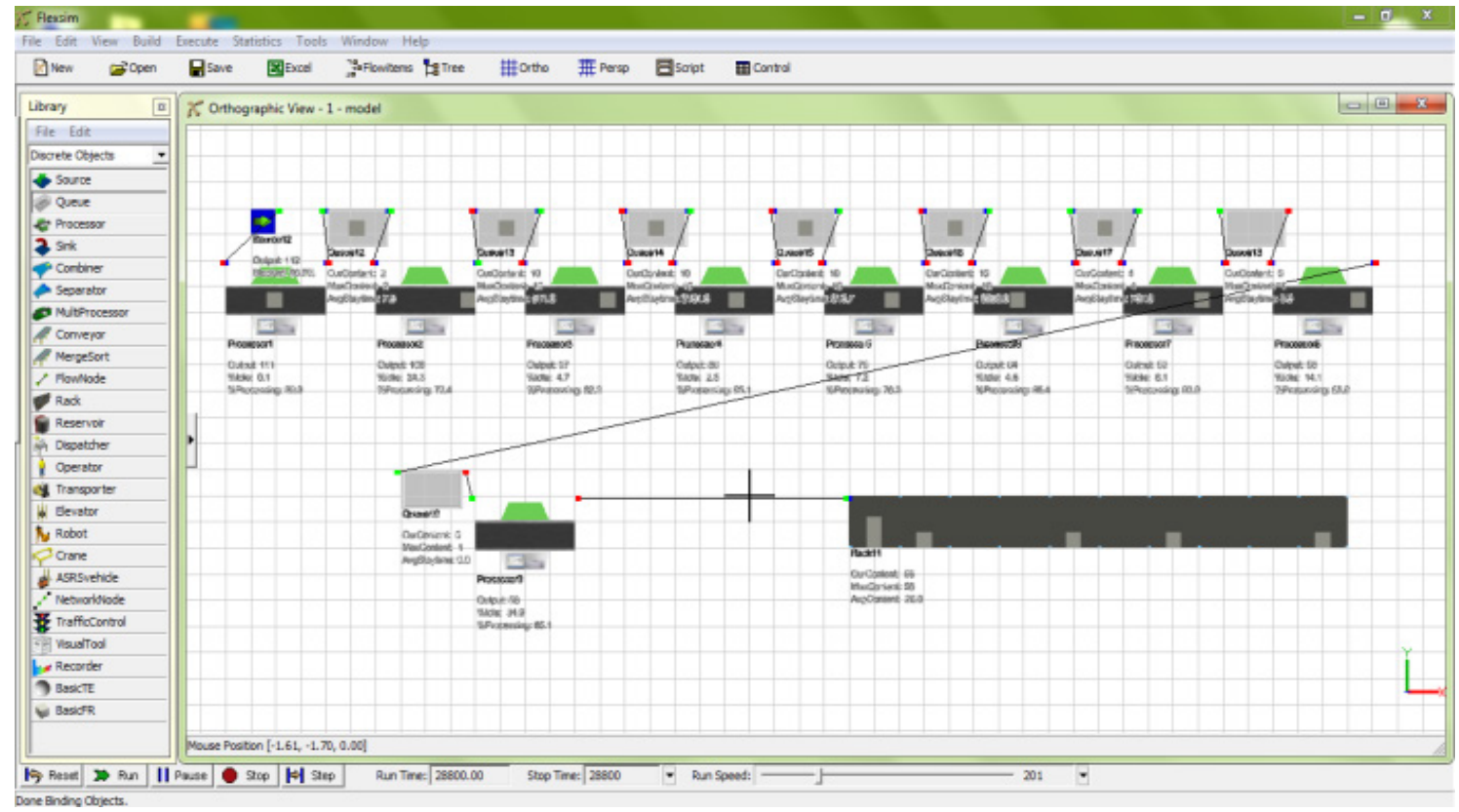

Figure 2. Simulated model of the assembling unit before applying modularity.

Average time required for assembling each component before applying modularity is: $452 \mathrm{sec}$.

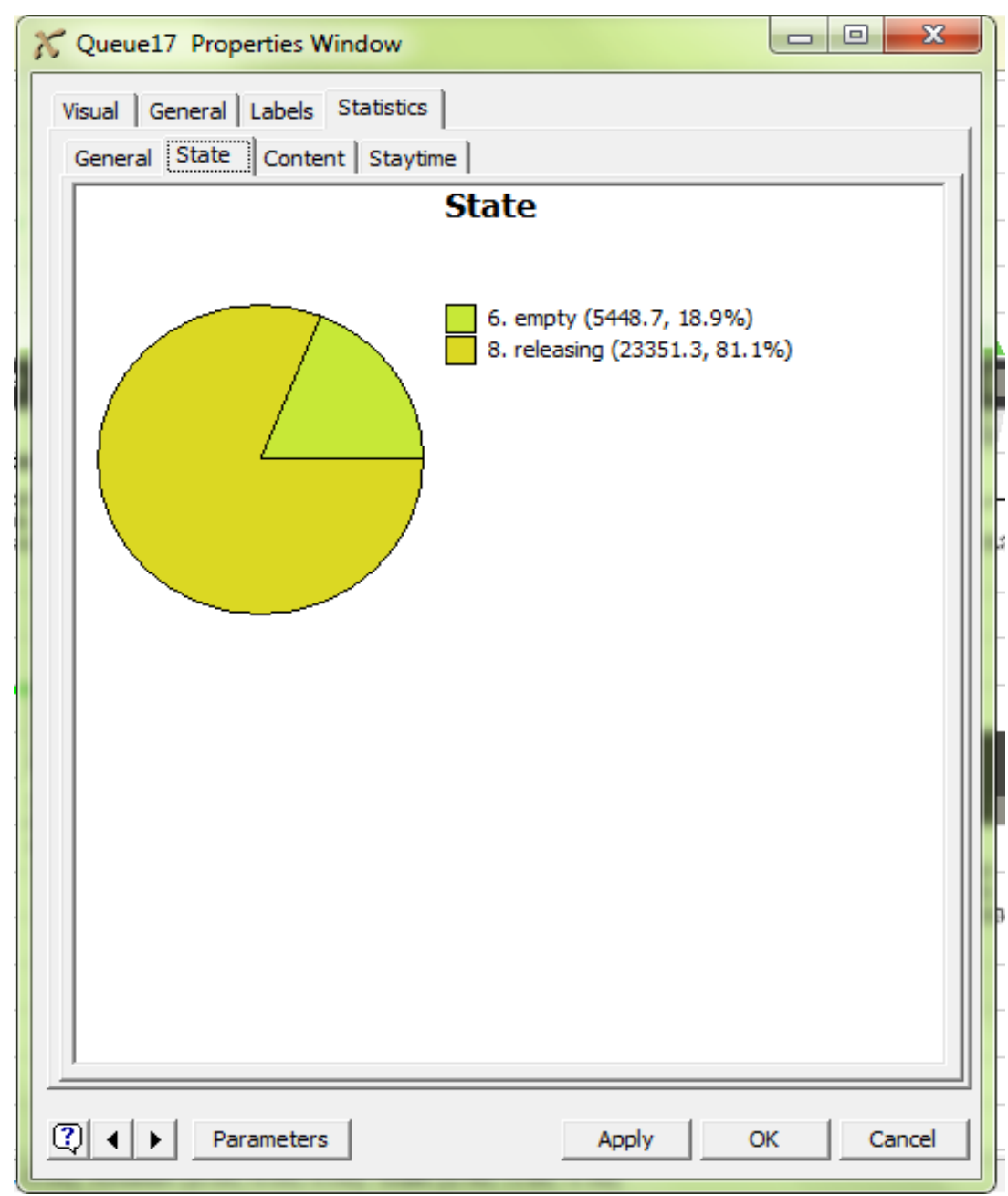

Number of Components Assembled in a day: 58 (Assuming 8 working hours / day).

Figure 3. Stack time at the Station 7. 


\section{Results and Discussion}

From the figure 3 , it is observed that the bottle neck station 7 is empty by $18.8 \%$ and releasing by $81.2 \%$. it was rectified by applying modular condition. The total parts assembled at station 7 (QSPV) is divided into simple modules, where the general components are assembled separately. It reduces the assembling time. Same has been observed from the Simulation results. The modified results after applying the modularity method describes the zero idle time. The number of components assembled increased by $7 \%$.These modifications are applied practically and got the best results.

Average time required for assembling each component after applying modularity is: $425 \mathrm{sec}$.

Number of Components Assembled in a day: 61 (Assuming 8 working hours per day).

Table 2. Total assembling time

\begin{tabular}{|c|c|c|}
\hline S1. No. & Station number & Time in sec. \\
\hline 1 & S1 & 258 \\
\hline 2 & S2 & 242 \\
\hline 3 & S3 & 316 \\
\hline 4 & S4 & 291 \\
\hline 5 & S5 & 426 \\
\hline 6 & S6 & 360 \\
\hline 7 & S7 & 420 \\
\hline 8 & S8 & 322 \\
\hline 9 & S9 & \\
\hline
\end{tabular}

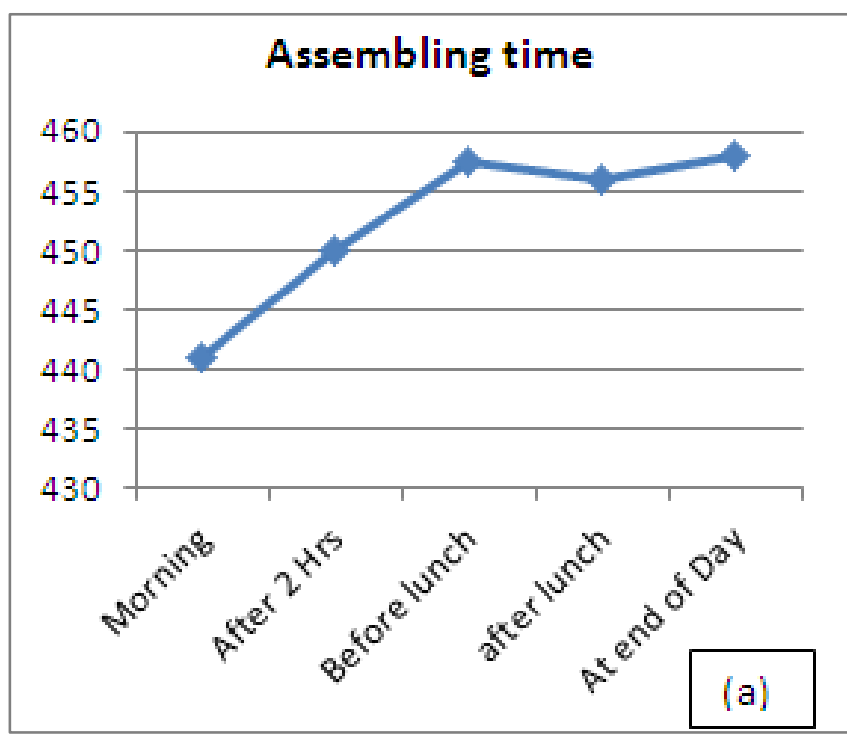

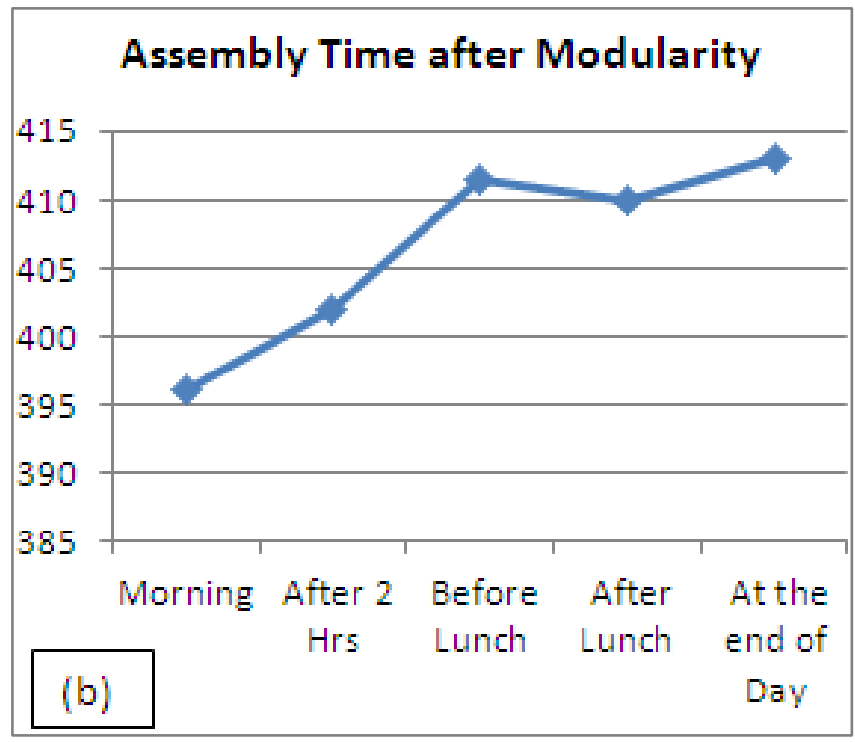

Figure 4. Time taken for assembling at different times of a day (a) before applying modularity (b) after applying modularity.

\section{Conclusions}

The conclusions drawn from the present study regarding modular assembly line over the non-modular assembly line can be described as follows:

- The main advantage of the modular assembly line seems to be the reduced lead time for the development of a new line. The reduction of lead time is achieved because the building phase of the development of a new modular system is shorter than the building phase of a non-modular system. In the non- modular line all stations must be present before any line testing can start.

- Without changing the design of the component optimisation is achieved.

- It is possible to increase the capacity of the modular assembly line system in a few steps by adding more stations.

- In addition, a certain proportion of the modular line stations can be reused for another project or sent to other factories to rebalance capacity.

- The total number of components has been increased and the assembling time has come down.

- The idle time for a given number of work stations for variable production rate is minimised.

\section{REFERENCES}

[1] Chow, W., (1990), Assembly Line Design: Methodology and Applications, Marcel Dekker, New York.

[2] Cooper, E. (1999). Modular assembly lines are taking over. Machine Design, 71(19), 97-102. 
[3] Fixson, S., K., (2002), The Multiple Faces of Modularity-An Analysis of a Product Concept for Assembled Hardware Products, Massachusetts: MIT

[4] Gershenson, J K, Prasad, G J and Zhang, Y (2004) Product modularity: measures and design methods, Journal of Engineering Design Vol 15 pp $33-51$

[5] He, D.W. and Kusiak, A., (1997), Design of assembly system for modular products. IEEE Tractions on Robotics and Automation, 13, 646-655.

[6] Heilala, J., Voho, P., (2001), Modular reconfigurable flexible assembly systems, Emerald (MCB), Assembly Automation Volume 21. Number 1. pp. 20 - 28, MCB University Press. ISSN 0144-5154

[7] John K. Gershenson and G. Jagannath Prasad, (1997), Modularity in product design for manufacturability. International Journal of Agile Manufacturing, Volume 1, Issue 1, August.
[8] L. P. Khoo and T. D. Situmdrang, (2003), Solving the assembly configuration problem for modular products using an immune algorithm approach, Int. J. Prod. Res., Vol. 41, no. $15,3419-3434$

[9] Nils Boysen, Malte Fliedner, Armin Scholl (2007), A classification of assembly line balancing problems. European Journal of Operational Research 183 (2007) 674-693

[10] Tsukune et al (1993) Modular manufacturing. Journal of Intelligent Manufacturing, 4, $163-181$.

[11] X. Lai \& J. K. Gershenson, (2007), Representation of similarity and dependency for assembly modularity. Int J Adv Manuf Technol Springer-Verlag London Limited.

[12] Z.M. Bi and W.J. Zhang, (2001), Modularity Technology in Manufacturing: Taxonomy and Issues, Int $\mathrm{J}$ Adv Manuf Technol 18:381-390 